\title{
Review of Cervical Carcinoma Screening Program in Tamil Nadu, the Current Trend and Recommendations from a Histopathologist's Viewpoint
}

\author{
Shifa S Ibrahim ${ }^{1}$, Kamaleshwari Kesavaraj ${ }^{2}$, Muthumani Arun ${ }^{3}$, Syed AM Ameen ${ }^{4}$, Raasi Sankar ${ }^{5}$
}

\begin{abstract}
Objective: Cervical carcinoma, the commonest carcinoma affecting Indian females, is caused by human papillomavirus (HPV) infection. Primordial prevention and primary prevention with HPV vaccine and cancer screening, respectively, can go a long way in preventing this carcinoma. The health system project in Tamil Nadu has done a commendable job in reducing the disease burden by introducing screening program for cervical carcinoma at the grassroots level way back in 2005. This study was done to evaluate the cervical biopsy specimens received as a part of this program to compute its incidence, compare the incidence among various districts, and suggest future directions based on our observations. Materials and methods: From the visual inspection with acetic acid (VIA)/visual inspection with Lugols iodine (VILI) positive cervical biopsy specimens, 506 were chosen randomly from various districts. Based on histopathological examination, incidence of individual lesions and district-wise incidence were calculated. Predictive factors that determine the progression of these lesions were analyzed based on the literatures. Results: Out of the 506 cervical biopsy specimens, 34 were unsatisfactory. The incidence of high-grade dysplasia peaked around 31-40 years and squamous cell carcinoma peaked among 51-60 years. Madurai ranked high in the incidence of both high-grade dysplasia and carcinoma. Conclusion: Incidence of dysplasia and carcinoma in our study was comparable with that seen in the literatures. Integration of HPV DNA studies into the program can increase the detection rate, detect the progressors, and helps in identifying the HPV species prevalent in an area and formulating cost-effective HPV vaccine cocktail.
\end{abstract}

Keywords: Acetowhite, Dysplasia, Human papillomavirus, Vaccine.

Journal of South Asian Federation of Obstetrics and Gynaecology (2019): 10.5005/jp-journals-10006-1735

\section{INTRODUCTION}

Cervical carcinoma is the first common carcinoma affecting the female population in India with an incidence of 134,420 new cases per year bearing one fifth of the world burden. ${ }^{1}$ It is seen among 15-44-yearold females. A total of $80 \%$ of the cases with cervical carcinoma are concentrated in the rural areas. ${ }^{2,3} A$ total of $87.8-96.67 \%$ of the invasive carcinoma was associated with human papillomavirus (HPV) infection. ${ }^{4}$ Cofactors that help in the progression from HPV infection to carcinoma include tobacco smoking, poor local hygiene, early coitus, multiple sexual partners, sexually transmitted disease, high parity, long-term use of contraceptives, and infection with HIV. To contain this preventable carcinoma, the government of Tamil Nadu initiated cervical cancer screening program as a pilot project in two districts way back in the year 2005. Now it has scaled up to include all the districts including urban and rural population.

Being a referral center, our department receives cervical biopsy specimens from camps organized in the nearby districts, district headquarters hospital, and from the hospital attached to our college. This study was undertaken to histopathologically analyze the specimens to find out the incidence of cervical dysplasia and carcinoma, its incidence among the districts from which we received the specimens, to analyze the progression factors in low-grade squamous intraepithelial lesion (LSIL) and high-grade squamous intraepithelial lesion (HSIL) cases and to formulate future goals in its control.

\section{Materials and Methods}

Tamil Nadu health system project had devised a method to screen the females for cervical cancer. It included visual inspection
${ }^{1-5}$ Department of Pathology, Madurai Medical College, Madurai, Tamil Nadu, India

Corresponding Author: Shifa S Ibrahim, Department of Pathology, Madurai Medical College, Madurai, Tamil Nadu, India, Phone: +91 9486669274, e-mail: shifafrin@gmail.com

How to cite this article: Ibrahim SS, Kesavaraj K, Arun M, et al. Review of Cervical Carcinoma Screening Program in Tamil Nadu, the Current Trend and Recommendations from a Histopathologist's Viewpoint. J South Asian Feder Obst Gynae 2019;11(6):356-362.

Source of support: Nil

Conflict of interest: None

with acetic acid (VIA)/ visual inspection with Lugols iodine (VILI), followed by cervical biopsy if VIA/VILI is positive. Both ectocervix and endocervical biopsies were performed. When the squamocolumnar junction is not made out, then endocervical biopsies were performed. The cervical biopsy specimen thus obtained from the camps organized by the Tamil Nadu government to prevent noncommunicable diseases, from clinics attached to the district hospitals, and from those who attended our collegeattached gynecology outpatient department were received in our department.

We had received 4,117 gynecological specimens per year. Out of that, 506 cervical biopsy specimens were randomly chosen from the different districts, processed routinely and examined by a team of expert pathologists. Based on histopathological examination, the specimens were categorized whether they were satisfactory or not. When the lining epithelium was absent or when there was 
only mucinous material, it was labeled as unsatisfactory. Those slides on which lining epithelium was seen, further screening was done to know whether the biopsy included squamous epithelium, columnar epithelium, endocervical glands, and stroma. When only endocervical glands and endocervical lining were seen, then it was sorted as endocervicitis. If both the linings were present, then normal epithelium/cervicitis/cervical dysplasia, LSIL and HSIL, and various types of carcinomas were diagnosed, categorized, and graded based on World Health Organization grading system. The incidences of various pathologies were tabulated. The incidences of these pathologies identified in different districts were categorized to find the region-wise variance in the incidence of these pathologies. Predictive factors that influence the progression of the diseases were also analyzed based on the literatures.

\section{Results}

Out of the 506 cervical biopsy specimens, 34 were unsatisfactory $(6.7 \%)$ and, hence, were excluded from our study. Out of the remaining 472 specimens, $75 \%$ of the cases were diagnosed as chronic cervicitis. The incidence of LSIL was $1.69 \%, 5.08 \%$ of the cases had high-grade intraepithelial lesion, and $6.4 \%$ of the cases had squamous cell carcinoma-grade II. Our study group comprised females of age groups 21-90 years. The mean age at which the biopsy was taken was 41.46 years. The incidence of high-grade dysplasia peaked around $31-40$ years, whereas the incidence of squamous cell carcinoma peaked among 51-60 years. Adenocarcinoma was seen in only $0.2 \%$ of the cases (Table 1 ).

More number of cervical biopsies were received from the Madurai district (65\%). The incidence of high-grade dysplasia and squamous cell carcinoma was also high in this district (13\%) followed by Sivagangai district (11\%). In the rest of the districts, only inflammatory pathologies were identified (Table 2).

\section{Discussion}

Squamous cell carcinoma and its precursor lesions-lowgrade intraepithelial neoplasm and high-grade intraepithelial neoplasm - are associated with HPV infection. Almost $80 \%$ of the females in their second decade harbor this infection and it declines to about $5 \%$ as they reach their fifth decade due to innate immunity. Human papillomavirus 16, 18, 31, 33, 35, 39, and 45 and HPV 6, 11, 40, 42 , and 43 come under high- and low-risk categories, respectively. 5,6 Human papillomavirus resides on the surface of the epithelium, and for an infection or viral DNA integration, this should reach the mitotically active basal layer which requires micro abrasion. After integration, HPV infection progresses to either low-grade or highgrade dysplasia or wane due to innate immunity. Later, low-grade or high-grade dysplasia may regress or progress to carcinoma.

Our study group included women aged between 21 years and 90 years with a mean of 41.46 years. Half of the women screened in our study groups belonged to both 31-40-year category and 41-50year category. In correlation with our study, in the study conducted by Poli et al., most of the women belonged to 31-40 years, and it was 30-39 years in Sankaranarayanan et al.'s study group. ${ }^{7,8}$ In Ghosh et al.'s study group, the mean age of the patients was $34.1 \pm 9.2$ years which was in correlation with our study. ${ }^{9}$

Low-grade intraepithelial lesion is usually asymptomatic. A total of $85 \%$ of the cases are associated with high-risk HPV. Grossly, they may be flat, present as squamous papilloma or as condylomas accuminata. ${ }^{10}$ Flat lesions are identified by acetowhitening and colposcopic examination of the cervix or by cytological screening as grossly no change is identifiable. Low-grade squamous intraepithelial lesion is classified histologically into mature and immature types. Mature type of LSIL consists of proliferating basal and parabasal cells involving one third of the epithelium representing a delay in the maturity of the cells with koilocytic atypia of the superficial layers. ${ }^{11,12}$ Sometimes, binucleation and multinucleation will be the only findings. In the immature LSIL type, there will be minimal atypia in the superficial layers and increased nuclear density throughout the epithelium (Fig. 1). Flat lesions are diffusely positive for p16, whereas papillary lesions show patchy p16 positivity denoting association with low-risk HPV infection. The incidence of LSIL was $1.69 \%$ in our study. It was $0.28 \%$ in Poli et al.'s study which was very less compared with the incidence observed in our study. ${ }^{7}$ A total of $50 \%$ of the cases diagnosed as LSIL were less than 50 years which was comparable with Poli et al.'s study. ${ }^{7}$ In Luthra et al.' study and Bhaskaran et al.'s study, the mean age at which LSIL was seen was 33.8 years and 31.4 years, respectively, which was comparable with our study. ${ }^{13,14}$ Low-grade squamous intraepithelial lesion lesions usually regress spontaneously; hence, regular follow-up is mandatory with cytology smears or HPV DNA testing every $6-12$ months. ${ }^{15}$

Like LSIL, flat high-grade intraepithelial lesion is also not visible grossly and is asymptomatic. It is identified by acetowhitening or Lugols iodine but confirmed only by histopathology. These lesions exhibit atypia in all layers of the epithelium, anisokaryosis, coarse nuclear chromatin, and abnormal mitotic figures (Fig. 2). Variants include keratinizing and papillary lesions. The incidence of HSIL was

Table 1: Age-wise stratification

\begin{tabular}{|c|c|c|c|c|c|c|c|c|}
\hline Age & $21-30$ years & $31-40$ years & $41-50$ years & $51-60$ years & $61-70$ years & $71-80$ years & $81-90$ years & Total \\
\hline $\mathrm{CC}^{*}$ & 65 & 136 & 85 & 36 & 8 & 23 & - & 353 \\
\hline $\mathrm{EC}^{\dagger}$ & 7 & 28 & 12 & 2 & - & 2 & - & 51 \\
\hline $\mathrm{LSIL}^{\ddagger}$ & - & 3 & 4 & - & - & - & 1 & 8 \\
\hline $\mathrm{HSIL}^{\S}$ & 4 & 8 & 3 & 6 & 2 & 1 & - & 24 \\
\hline $\operatorname{SCC} 1 \|$ & - & - & 1 & 1 & - & - & - & 2 \\
\hline SCC $11^{\square}$ & 1 & 3 & 11 & 7 & 6 & 2 & - & 30 \\
\hline$A C^{* *}$ & - & - & - & 1 & - & - & - & 1 \\
\hline $\mathrm{PC}^{+\dagger}$ & - & - & 1 & 1 & 1 & - & - & 3 \\
\hline$U^{\neq \neq}$ & 3 & 12 & 12 & 6 & 1 & - & - & 34 \\
\hline Total & 80 & 190 & 129 & 60 & 18 & 28 & 1 & 506 \\
\hline
\end{tabular}

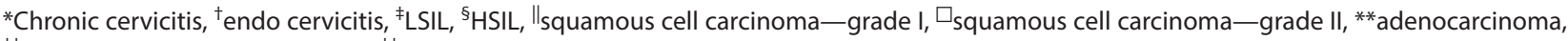

${ }^{+\dagger}$ poorly differentiated carcinoma, ${ }^{, \neq}$unsatisfactory 


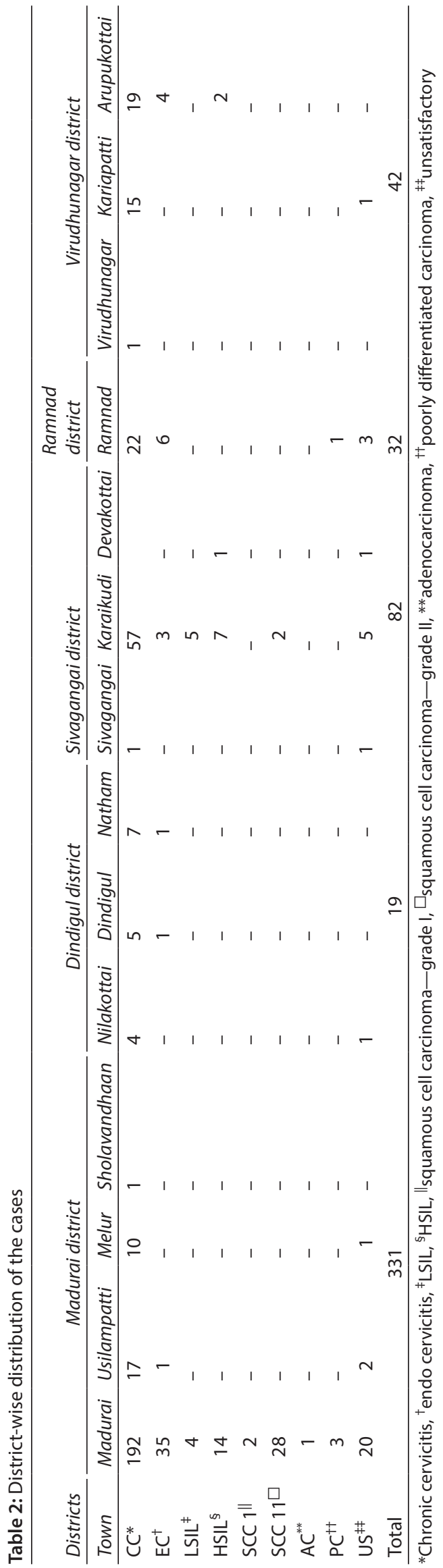

$5.08 \%$ in our study which was comparable with other studies (1.0527.4\%). ${ }^{7,16,17}$ Peak incidence of HSIL was seen in 31-40-year group which was similar to Sankaranarayanan et al.'s study group. ${ }^{8}$ The mean age at which cervical intraepithelial neoplasia (CIN) II and III were detected was 35.2 and 40.2 years, respectively, in Luthra et al.'s study and 34.3 years in Bhhaskaran et al.'s study which was similar to our study. 13,14 The ratio of detection of LSIL to HSIL in our study group was 0.3:1 which was also observed in the study conducted in England and Australia, and it was higher in Sankaranarayanan et al.'s study group (8.1:1). 8,18,19 Treatment of HSIL includes cone biopsy, cryotherapy, or loop electrosurgical excision procedure.

Both LSIL and HSIL have a chance of regression. According to Nasiell et al., $62 \%$ of the cases with LSIL will regress and $50 \%$ of CIN II cases regress according to another study by Nasiell et al., and it progresses to high-grade lesions or carcinoma in $16 \%$ of the cases and $35 \%$, respectively. ${ }^{20,21}$ In India, HPV prevalence is common among 26-35-year-old females, and carcinoma occurs around 45-59-year-olds. ${ }^{22}$ Effective intervention in this 20-year window period can prevent the progression of this carcinoma. The cytological and histopathological regression along with spontaneous HPV DNA negativity is possible in $95 \%$ of the cases. ${ }^{23}$ Only those with persistent HPV infection often progress to the next stage. Histopathological predictors of progression to squamous carcinoma include extensive involvement of surface epithelium and deep endocervical crypts by HSIL, luminal necrosis, intraepithelial squamous maturation, papillary architecture, mucin differentiation, and fibroblastic proliferation of the stroma. ${ }^{24}$ According to Koeneman et al.'s study, nonsmokers, prebiopsy PAP 3a and a concomitant LSIL in the biopsy and not more than one biopsy containing CIN2 were predictors of spontaneous regression. ${ }^{25}$ Several markers are on trial to predict the progression. Sirtulin 1 (SIRT1) and p16 are the immunohistochemical markers helpful to assess the disease progression. ${ }^{26}$

Grossly, squamous cell carcinoma presents as a friable exophytic or an ulcerated lesion. Histopathologically, the tumor is composed of sheets of cells with nuclear irregularity, prominent nucleoli, and show brisk mitosis and invasion into the stroma (Fig. 3). The variants include keratinizing type, non-keratinizing type, small cell, basaloid squamous, verrucous, warty, squamotransitional, and lymphoepithelioma-like carcinoma. The incidence of squamous cell carcinoma in our study group peaked around 51-60 years which was also observed in Sankaranarayanan et al.'s study group. ${ }^{8}$ In Bhaskaran et al.'s study, the age group affected with carcinoma in situ was 34.7 years and with invasive carcinoma 42.2 years, respectively, which was comparable with our study. ${ }^{14}$

Adenocarcinoma of the cervix arises from an in situ lesion. Most adenocarcinoma is associated with HPV types 16 and 18. Grossly, the tumor is either exophytic or ulcerated. Histopathologically, the tumor is composed of confluent cribriform glands, apical mucin depletion, and pseudo stratification (Fig. 4). Variants include mucinous, villoglandular, endometrioid, clear cell, serous, adenoid basal, adenoid cystic, and mesonephric carcinoma. The incidence of adenocarcinoma of the cervix has increased in the developed countries as squamous cell carcinoma incidence is declining due to effective cervical screening program. Major hindrance in the detection of the precursor lesions of adenocarcinoma is inaccessible columnar epithelium by cytology and colposcopy. Relatively, it is easier to detect precursor squamous carcinoma lesions as the squamous lining is well exposed to screening. The incidence of adenocarcinoma was $14 \%$ of all carcinomas of the cervix according to Greer et al., whereas in our study, the incidence was $0.2 \%{ }^{27}$ 


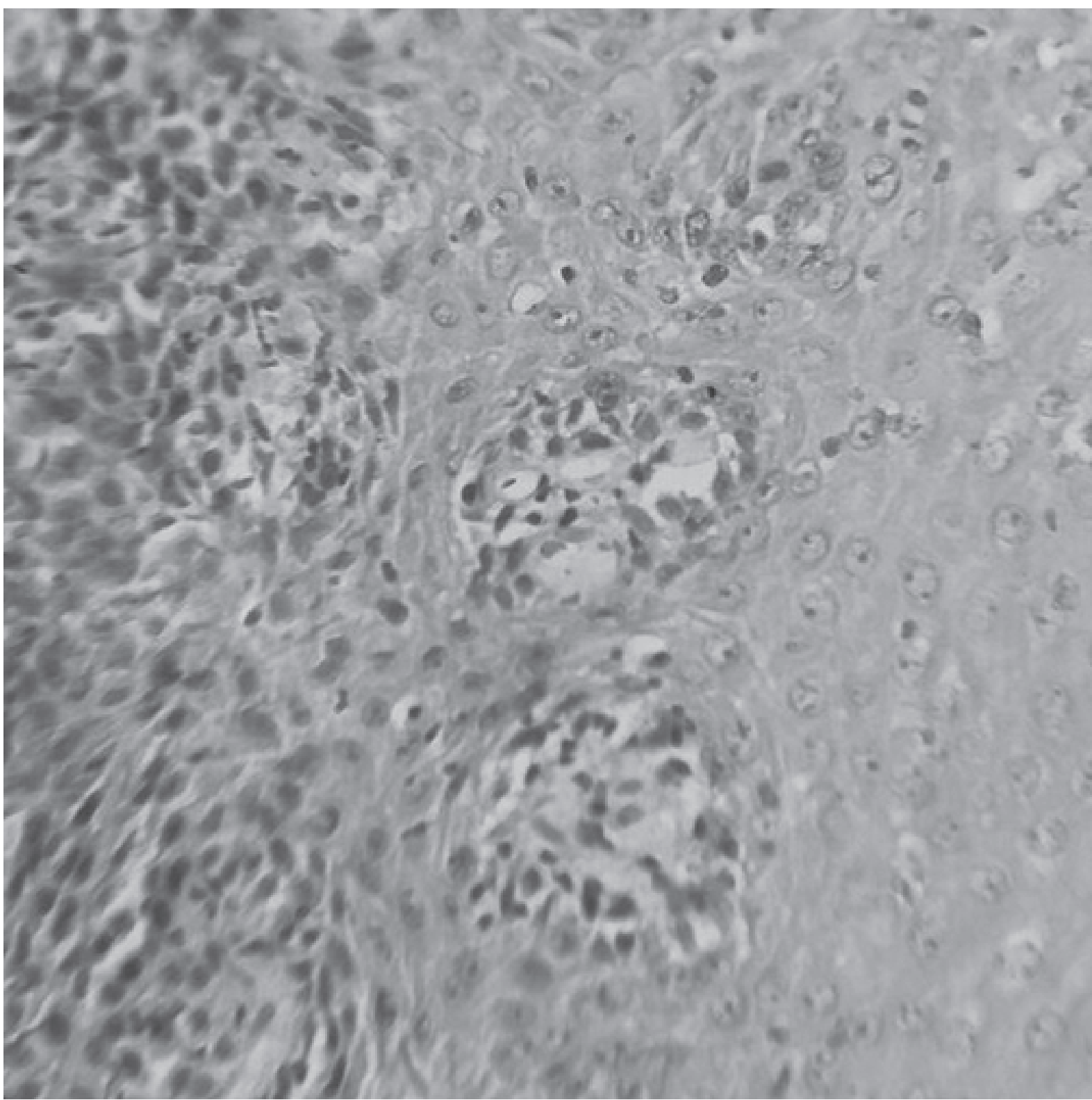

Fig. 1: This shows increased nuclear density of all the layers with minimal atypia in the superficial layers-low-grade squamous intraepithelial lesion, immature type $(\mathrm{H} \& \mathrm{E}, 40 \times)$

Treatment of both squamous cell carcinoma and adenocarcinoma of the cervix includes radical hysterectomy and lymphadenectomy with or without chemoradiation depending on the stage of the tumor.

Cervical carcinoma can be prevented by early screening methods. Most cases of cervical carcinoma were diagnosed after opportunistic screening, that is after the patient develops symptoms. To prevent the occurrence of cervical carcinoma among the highrisk females and thereby to prevent cervical cancer-related deaths, the Government of Tamil Nadu had initiated a project to screen all sexually active females from both the urban and rural backgrounds. ${ }^{28}$ Protocols were devised by experts under the guidance of Tata Memorial Hospital, Mumbai, and Adyar Cancer Institute, Chennai, and approved by World Bank. Awareness program was organized to mobilize the population and to accept the program.
The project includes magnified visual inspection with 3-5\% acetic acid (VIA) and VILI if positive followed by histological sampling. A well-demarcated opaque lesion due to increased intracellular protein content located in the transformation zone close to the squamocolumnar junction is taken as VIA test positive (Fig. 5). When there is no whitening, faint, or dot-like positivity, endocervical polyps, nabothian cysts, or a prominent squamocolumnar junction, then they are taken as negative VIA. lodine non-uptake areas or if the cervix is densely yellow, it is taken as VILI positive (Fig. 6). The transformation zone in the cervix represents the squamous metaplastic zone where the resting reserve cells in response to injury proliferate and form immature squamous cells. These cells do not form glycogen and, hence, does not stain with iodine. This is identified by the iodine test. These metaplastic cells are prone for HPV infection and, hence, progress 


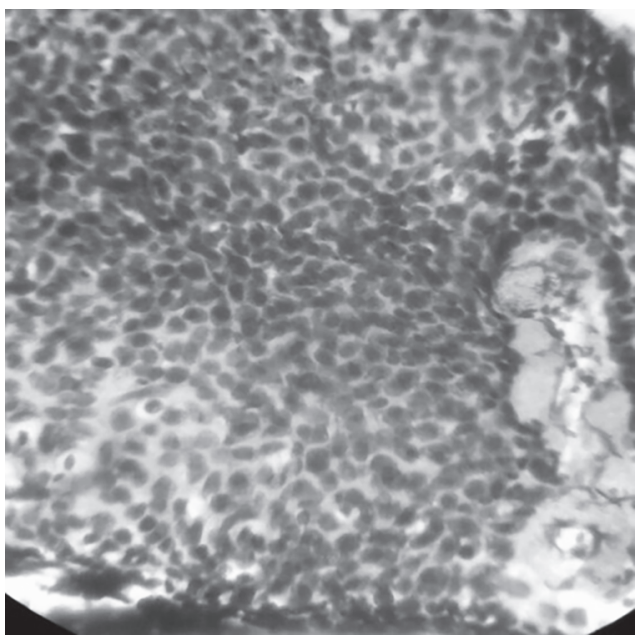

Fig. 2: This shows marked atypia of all the layers with intact basement membrane-high-grade squamous intraepithelial lesion (H\&E, 40X)

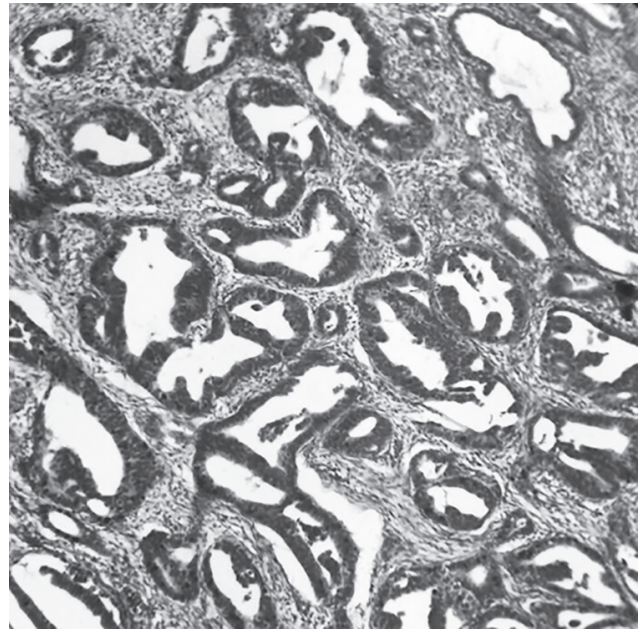

Fig. 4: This shows tumor cells arranged in glandular pattern with loss of mucin and shows nuclear stratification-adenocarcinoma (H\&E, 40X)

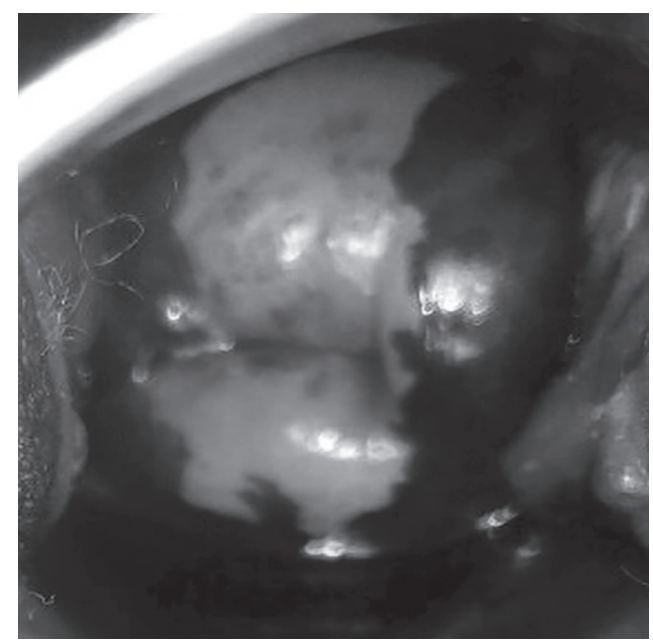

Fig. 6: This shows a yellow area in the cervix-positive visual inspection with Lugols iodine

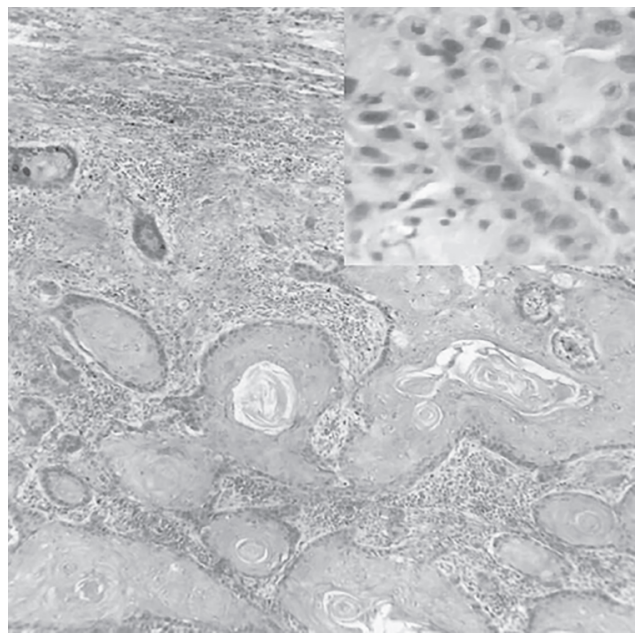

Fig. 3: This shows atypical squamous cells invading the stroma with inflammatory stromal reaction (H\&E, 10X). Inset shows pleomorphic squamous cells—squamous cell carcinoma-grade I (H\&E, 40X)

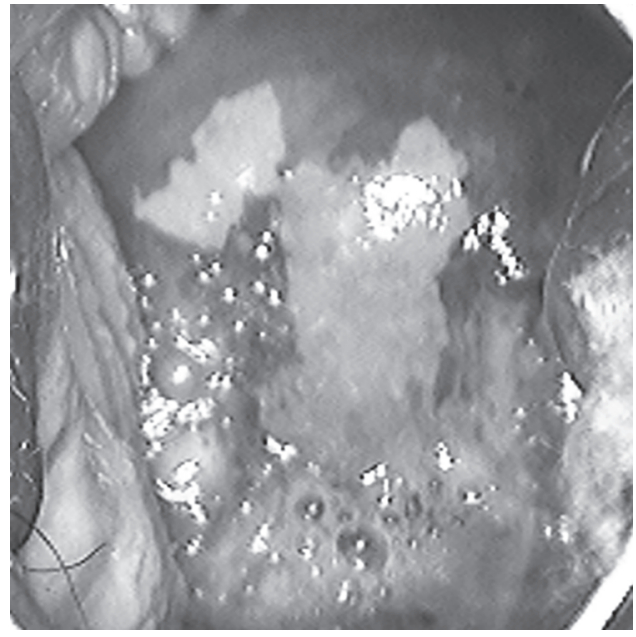

Fig. 5: This shows an opaque circumscribed patch in the cervix-positive visual inspection with Lugols iodine

to form dysplastic cells and carcinoma. The sensitivity of VIA/VILI to detect HSIL was $66-96 \%$, and the specificity was $64-98 \%$. The sensitivity of VIA/VILI was found to be similar to that of cytology, whereas its specificity was more, and hence, it was implemented in the place of cytological screening.

Recently, HPV DNA tests are introduced along with cervical screening in the developed countries. This can identify those who might develop intraepithelial lesions. But because of its high cost, implementing it in the developing countries like us is not possible now. Stoler et al. in their study had analyzed the diagnostic interpretation of the biopsy cervix of both community pathologists and an expert panel and had concluded that incorporation of HPV and immunohistochemical markers like p16 can improve the diagnosis and, hence, can appropriately guide the treating physicians. ${ }^{29}$ As follow-up of patients with LSIL and HSIL is difficult in our setup as it needs more community motivation, implementation of HPV tests and ancillary prognostic tests are needed as it mitigates the need for follow-up, and it can be 
cost-effective if done with dedication and refined implementation methodologies.

Higher turnover and higher incidence of dysplasia was seen in Madurai district. Because Madurai is the epicenter of this district, it might have received maximum number of cases, and our hospital being a referral center, the higher incidence might be due to pooling of cases from the nearby areas. There was a region-wise variability in the prevalence of HPV. According to Bhatla et al.'s study, HPV 45 was more prevalent in the southern states compared with northern states. ${ }^{30}$ Such variation might also exist among various districts, thereby leading to the increased prevalence of carcinoma in certain districts which might be the second reason for higher incidence in Madurai district. This could be ascertained with certainty only if HPV DNA assay is integrated in our program. This though increase the cost of screening, in a long run, it can help in identifying the areas where high-risk HPV is prevalent, and hence, concentrated approach can be given to that area. This can also help us to formulate individual area-wise HPV strain vaccine cocktails to prevent such infections.

\section{Conclusion}

In our study, the incidence of HSIL peaked around 31-40 years and squamous cell carcinoma peaked around $51-60$ years. This implicates that HPV infection in those before 30 years wane, and in this 20-year window period, populations are more likely to develop carcinoma. This population can be targeted for HPV screening and analyzing the type of HPV prevalent in them, persistence of HPV infection in them, percentage of progressors, and the type of HPV more likely to cause carcinoma which is more cost-effective than screening the entire populations with HPV DNA in addition to the histopathological examination. This can guide us to formulate the vaccine cocktail specific to a particular district based on the HPV strains prevalent in that district. The benefit is more compared with cost in this methodology.

\section{ACKnOWLedgments}

Authors acknowledge the support given by their Professor and Head of the Department Dr Geetha T, M.D. (Pathology) and thank all the technical staffs and the workers in their department for giving us a helping hand.

\section{References}

1. Indian Council of Medical Research. National cancer registry programme, twoyear report of the hospital based cancer registries 19992000. Bangalore: ICMR; 2005: 3.

2. Moreno V, Bosch FX, Muñoz N, et al. Effect of oral contraceptives on risk of cervical cancer in women with human papillomavirus infection: The IARC multicentric case-control study. Lancet 2002;359(9312):1085-1092. DOI: 10.1016/S0140-6736(02)08150-3.

3. Koskela P, Anttila T, Bjørge T, et al. Chlamydia trachomatis infection as a risk factor for invasive cervical cancer. Int J Cancer 2000;85(1):35-39. DOI: 10.1002/(SICI)1097-0215(20000101)85:1<35::AID-IJC6>3.0.CO;2-A.

4. Sowjanya AP, Jain $M$, Poli UR, et al. Prevalence and distribution of high-risk human papilloma virus (HPV) types in invasive squamous cell carcinoma of the cervix and in normal women in Andhra Pradesh, India. BMC Infect Dis 2005;5:116. DOI: 10.1186/1471-2334-5-116.

5. Kovacic MB, Castle PE, Herrero R, et al. Relationships of human papillomavirus type. Qualitative viral load, and age with cytologic abnormality. Cancer Res 2006;66:10112-10119. DOI: 10.1158/00085472.CAN-06-1812.
6. Lorincz AT, Reid R, Jenson AB, et al. Human papillomavirus infection of the cervix: relative risk associations of 15 common anogenital types. Obstet Gynecol 1992;79(3):328-337. DOI: 10.1097/00006250199203000-00002.

7. Poli UR, Bidinger PD, Gowrishankar S. Visual Inspection with Acetic Acid (VIA) Screening Program: 7 Years' experience in early detection of cervical cancer and pre-cancers in rural south India. Indian J Community Med 2015;40(3):203-207. DOI: 10.4103/0970-0218.158873.

8. Sankaranarayanan R, Rajkumar R, Theresa R, et al. Initial results from a randomized trial of cervical visual screening in rural south India. Int. J. Cancer 2004;109(3):461-467. DOI: 10.1002/ijc.11726.

9. Ghosh P, Gandhi G, Kochhar PK, et al. Visual inspection of cervix with Lugol's iodine for early detection of premalignant \& malignant lesions of cervix. Indian J Med Res 2012;136(2):265-271.

10. Blomberg M, Friis S, Munk C, et al. Genital warts and risk of cancer: a Danish study of nearly 50000 patients with genital warts. J Infect Dis 2012;205(10):1544-1553. DOI: 10.1093/infdis/jis228.

11. Koss LG, Durfee GR. Unusual patterns of squamous epithelium of the uterine cervix: cytologic and pathologic study of koilocytic atypia. Ann NY Acad Sci 1956;63:1245-1261. DOI: 10.1111/j.1749-6632.1956. tb32134.x.

12. Meisels A, Fortin R. Condylomatous lesions of the cervix and vagina.1. Cytotogical patterns. Acta Cytol 1976;20(6):505-509.

13. Luthra UK, Prabhakar AK, Seth P, et al. Natural history of precancerous and early cancerous lesions of the uterine cervix. Acta Cytol 1987;31(3):226-234.

14. Bhaskaran CS, Bhagyalakshmi M, Rani LU. Premalignant and malignant lesions of cervix. Indian J Med Res 1978;67:97-105.

15. Cox JT, Schiffman M, Solomon D, et al. Prospective follow-up suggests similar risk of subsequent cervical intraepithelial neoplasia grade 2 or 3 among women with cervical intraepithelial neoplasia grade 1 or negative colposcopy and directed biopsy. Am J Obstet Gynecol 2003;188(6):1406-1412. DOI: 10.1067/mob.2003.461.

16. Sankaranarayanan R, Basu P, Wesley R, et al. Accuracy of visual screening for cervical neoplasia: results from an IARC multicentre study in India and Africa. Int J Cancer 2004;110(6):907-913. DOI: 10.1002/ijc.20190.

17. Basu PS, Sankaranarayanan R, Mandal R, et al. Visual inspection with acetic acid and cytology in the early detection of cervical neoplasia in Kolkata, India. Int J Gynecol Cancer 2003;13:626-632. DOI: 10.1136/ ijgc-00009577-200309000-00009.

18. Patnick J. Cervical cancer screening programme 2000. Reducing the risk. NHS Cervical cancer screening programme. National Health Service, Sheffield, UK 2000.

19. Australian Institute of Health and Welfare. Cervical cancer screening in Australia 1997-1998. AlHW Cat No 9. Canberra: Australian Institute of Health and Welfare; 2000.

20. Nasiell K, Roger V, Nasiell M. Behaviour of mild cervical dysplasia during long-term follow-up. Obstet Gynecol 1986;67(5):665-669. DOI: 10.1097/00006250-198605000-00012.

21. Nasiell K, Nasiell M, Vaclavinková V. Behaviour of moderate cervical dysplasia during long-term follow-up. Obstet Gynecol 1983;61(5):609-614.

22. Disease Specific Documents for XII plan. Human Papilloma Virus ICMR: High power Committee to Evaluate Performance of ICMR, 2012-2013. New Delhi, India: ICMR; 2014.

23. Hildescheim A, Schiffman MH, Gravit PE, et al. Persistence of type specific human pappiloma virus infections among cytologically normal women. J Infect Dis 1996;174:927-936. DOI: 10.1093/ infdis/174.5.927.

24. Tidbury $P$, Singer $A$, Jenkins $D$. CIN 3: the role of lesion size in invasion. Br J Obstet Gynaecol 1992;99(7):583-586. DOI: 10.1111/j.14710528.1992.tb13825.x.

25. Koeneman MM, van Lint FHM, van Kuijk SMJ, et al. A prediction model for spontaneous regression of cervical intraepithelial neoplasia grade 2, based on simple clinical parameters. Hum Pathol 2017;59:62-69. DOI: 10.1016/j.humpath.2016.09.012. 
26. Velez-Perez A, Wang XI, Li M, et al. SIRT1 overexpression in cervical squamous intraepithelial lesions and invasive squamous cell carcinoma. Hum Pathol 2017;59:102-107. DOI: 10.1016/j.humpath.2016.09.019.

27. Greer BE, Figge DC, Tamimi HK, et al. Stage IB adenocarcinoma of the cervix treated by radical hysterectomy and pelvic lymph node dissection. Am J Obstet Gynecol 1989;160(6):1509-1514. DOI: 10.1016/0002-9378(89)90877-6.

28. Goldie SJ, Gaffkin L, Goldhaber-Fiebert JD, et al. Costeffectiveness of cervical cancer screening in fve developing countries. N Engl J Med 2005;353(20):2158-2168. DOI: 10.1056/ NEJMsa044278.

29. Stoler MH, Ronnett BM, Joste NE, et al. The Interpretive variability of cervical biopsies and its relationship to HPV status. Am J Surg Pathol 2015;39(6):729-736. DOI: 10.1097/PAS.0000000000000381.

30. Bhatla N, Lal N, Bao YP, et al. A meta-analysis of human papillomavirus type-distribution in women from South Asia: implications for vaccination. Vaccine 2008;26(23):2811-2817. DOI: 10.1016/ j.vaccine.2008.03.047. 